\section{Immunolocalization of NGF and its receptors in ovarian surface epithelium of the wild ground squirrel during the breeding and nonbreeding seasons}

\author{
L. Bao, ${ }^{1}$ Q. Li, ${ }^{2}$ Y. Liu, ${ }^{2}$ B. Li, ${ }^{2}$ X. Sheng, ${ }^{2}$ \\ Y. Han, ${ }^{2} Q$. Weng ${ }^{2}$ \\ 'Institute of Public Health, Inner \\ Mongolia University for Nationalities, \\ Tongliao, China \\ 'Laboratory of Animal Physiology, \\ College of Biological Sciences and \\ Technology, Beijing Forestry University, \\ Beijing, China
}

\section{Abstract}

The ovarian surface epithelium (OSE) plays an important role in normal ovarian physiology. During each reproductive cycle, the OSE takes part in the cyclical ovulatory ruptures and repair. The aim of this study was to investigate the immunolocalization of nerve growth factor (NGF) and its receptors, tyrosine kinase A (TrkA) and p75, in the OSE cells of the wild ground squirrels during the breeding and nonbreeding seasons. There were marked variations in ovarian weight and size between the breeding and the nonbreeding seasons. Histologically, cuboidal cells and squamous cells were identified in the OSE of both seasons. Yet, stronger immunostaining of NGF, TrkA and p75 were observed in cuboidal cells and squamous cells in the breeding season as compared to the nonbreeding season. In addition, plasma gonadotropin concentrations were higher in the breeding season than in the nonbreeding season, suggesting that the expression patterns of NGF, TrkA and p75 in the OSE were correlated with changes in plasma gonadotropins. These findings suggested that NGF and its receptor TrkA and p75 may be involved in the regulation of seasonal changes in the OSE of wild ground squirrel.

\section{Introduction}

The ovarian surface epithelium (OSE) is a single mesothelial layer of cuboidal and squamous cells, which is derived from the coelomic layer along with the lining of the peritoneal cavity. ${ }^{1}$ Cell proliferation occurs at the epithelial surface above the developing preovulatory follicle to accommodate the increase in follicular size, and again after ovulation, to repair the surface. ${ }^{2}$ Electron microscopy of normal human ovaries reveals that the epithelium consists of two distinct cell types, cuboidal type A cells and squamous type B cells, each occupying discrete zones in the epithelium. These two cell types are observed in both mouse $\mathrm{e}^{3,4}$ and human OSE. $^{5}$ Cuboidal cells may divide and migrate to cover the wound site caused by ovulation; and squamous cells would be expected to increase as the number of ovulations increased. ${ }^{4,5}$ Human OSE appears to differ from mouse OSE in that human type B cells are associated with past ovulation episodes. During the reproductive life of a woman, invagination of the surface epithelium into the cortical stroma gives rise to epithelial crypts and inclusion cysts. ${ }^{6}$ These structures are considered preneoplastic and may facilitate malignant transformation of entrapped OSE by generating a microenvironment enriched with growth factors, cytokines and hormones. ${ }^{7,8}$ The OSE cells also secrete chymotrypsin-like and elastase-like peptidases, metalloproteases and plasminogen activator inhibitor, which may facilitate ovulatory rupture in vivo. ${ }^{9}$ Notably, the OSE expresses integrins that bind to laminin, collagens, fibronectin and vitronectin, and these interactions may play a role in the adhesion, spreading, proliferation and matrix reconstitution of normal OSE following postovulatory ruptures. As the ovary is a rich source of multiple hormones, and normal OSE and ovarian carcinomas secrete and have receptors for hormones, growth factors and cytokines, these factors are strong candidates to regulate normal OSE physiology and the transformation and progression of ovarian cancers. ${ }^{6}$

Nerve growth factor (NGF) is one kind of neurotrophins (NTs) which are mainly involved in the survival and development of discrete neuronal populations in the central and peripheral nervous system. ${ }^{10}$ The biological function of NGF requires two receptors: p75 and tyrosine kinase A (TrkA). P75 is the low affinity receptor for NGF and belongs to the tumor necrosis factor receptor superfamily. ${ }^{11}$ TrkA is the high affinity receptor for NGF and belongs to the tyrosine protein kinase receptor family. ${ }^{12}$ Accumulating studies to date suggest that the function of NGF is not only limited to the nervous system, but also extends to nonnervous systems, including the male and female reproductive systems. ${ }^{13-15}$ Evidence indicates that NGF and its receptors play a critical role in development of the mammalian ovary, oogenesis and folliculogenesis. ${ }^{16-21}$ However, the expressions of NGF and its receptors TrkA and p75 in the OSE of a seasonal breeder are unclear.
Correspondence: Dr. Lihong Bao, Institute of Public Health, Inner Mongolia University for Nationalities, Tongliao 028000 , China.

Tel. +86.475.8314234 - Fax: +86.475.8314234.

E-mail: baolihong@imun.edu.cn

Keywords: ground squirrel, NGF, OSE, p75, TrkA.

Conflict of interests: the authors declare no conflict of interests.

Contributions: $\mathrm{QW}$, experiments conceiving and design; LB, QL, XS, experiments performing; YL, $\mathrm{YH}$, data analysis; LB, QW, manuscript design and writing. All authors approved the final version.

Acknowledgments: this study was partially supported by a Grant-in-Aid from Changjiang Scholars and Innovative Research Team in Universities (IRT0607) from China.

Received for publication: 8 January 2014. Accepted for publication: 12 March 2014

This work is licensed under a Creative Commons Attribution NonCommercial 3.0 License (CC BYNC 3.0).

(C) Copyright L. Bao et al., 2014

Licensee PAGEPress, Italy

European Journal of Histochemistry 2014; 58:2363 doi:10.4081/ejh.2014.2363

The wild ground squirrel (Citellus dauricus Brandt) is a typical seasonal breeder which have a strict and extremely compressed breeding period (for females, it consists of estrous period and pregnancy) from April to May and a long period of sexual dormancy from June to the following March including a 6-month hibernation period. ${ }^{22}$ The wild female ground squirrel exhibits estrus immediately after emergence from hibernation in spring, and has a gestation period of 28 days. ${ }^{23,24}$ Although many observations on the regulatory roles of NGF and its receptors on ovarian function exist, the mechanisms of ovarian function and especially its role in the seasonal ovarian function changes, such as OSE cell survival and differentiation are not well understood. Our previous study found that immunoreactivities of NGF, TrkA and p75 in the ovary were high in the breeding season and then decreased in the nonbreeding season, suggesting that they may be involved in regulation of seasonal ovarian function changes in the wild ground squirrel..$^{25}$ To test that hypothesis, we evaluated the morphology of OSE and the immunolocalization of NGF and its receptors trkA and p75 in OSE of the wild ground squirrel during breeding and nonbreeding periods and thereby gained a better understanding of the relationship between NGF system and OSE function changes in the wild ground squirrel. 


\section{Materials and Methods}

\section{Animals}

All animal procedures were carried out in accordance with the Policy on the Care and Use of Animals by the Ethical Committee, Beijing Forestry University and approved by the Department of Agriculture of Hebei province, China (JNZF11/2007). Adult wild female ground squirrels (body weight between 242 and $412 \mathrm{~g}$ ) were captured between April 13 and 20 (10.2 h of daylight) after emergence from hibernation in the breeding period $(\mathrm{n}=10)$ and on June 9 (12.6 h of daylight) in the nonbreeding period $(n=8)$ of 2009 in Hebei Province, China. Animals were anesthetized with $4 \%$ isoflurane and blood samples were rapidly collected from a leg vein with heparin sodium. Plasma samples were frozen and stored at $-20^{\circ} \mathrm{C}$, after the blood samples were centrifuged $\left(3000 \mathrm{~g}, 20 \mathrm{~min}\right.$ at $\left.4^{\circ} \mathrm{C}\right)$. An overdose of pentobarbital (BioDee Co., Beijing, China) was applied afterwards for euthanasia. Ovaries were quickly removed and dissected. Length, width and weight of each ovary were measured. One ovary from each animal was fixed in $0.05 \mathrm{M}$ phosphate-buffered saline (PBS, pH 7.4) containing 4\% paraformaldehyde for histological and immunohistochemical observations. The remaining ovaries were viewed by scanning electron microscopy (SEM).

\section{Histology}

Ovarian samples were dehydrated in ethanol series and embedded in paraffin wax. Serial sections ( $4 \mu \mathrm{m}$ ) were mounted on slides coated with poly-L-lysine (Sigma Chemical Co., St. Louis, MO, USA). Observations of general histology were by standard hematoxylineosin (HE) staining. The sections were screened using an Olympus photomicroscope with $\mathrm{a} \times 20$ objective lens and imaged with software Image-Pro Plus 4.5 (Media Cybernetics, Bethesda, MD, USA). Every one in ten serial sections, and altogether 50 and 30 sections for the breeding and nonbreeding season ovary respectively were selected for follicle identification and quantification. Six random vision fields were selected per section.

\section{Scanning electron microscopy}

Following dissection, ovaries were fixed in $2.5 \%(\mathrm{v} / \mathrm{v})$ gluteraldehyde and $1 \%(\mathrm{v} / \mathrm{v})$ osmium, and then dehydrated through a graded ethanol series. After the critical point-dried was carried out, the tissues were mounted on aluminum stubs and sputter-coated with gold palladium and then observed using a Hitachi S34Q SEM (Hitachi Corp., Tokyo, Japan).

\section{Immunohistochemistry}

The ovarian serial sections were incubated with $10 \%$ normal goat serum to reduce nonspecific binding of primary antibodies and background staining caused by the secondary antibody. The sections were then incubated with polyclonal primary antibody against NGF (0.4 $\mathrm{lg} / \mathrm{mL}, \mathrm{M}-20)$, TrkA (2 lg/mL, 763) or p75 (2 lg/mL, H-92) (Santa Cruz Biotechnology, Santa Cruz, CA, USA) for $12 \mathrm{~h}$ at $4^{\circ} \mathrm{C}$, and incubated with the second antibody, goat anti-rabbit IgG conjugated with biotin and peroxidase with avidin for $1 \mathrm{~h}$ at room temperature. The sections were visualized using a rabbit ExtrAvidin $^{\mathrm{TM}}$ staining kit (Sigma) in $150 \mathrm{~mL}$ of $0.05 \mathrm{M}$ Tris-HCl buffer containing $30 \mathrm{mg} \mathrm{3,3-}$ diaminobenzidine (Wako, Tokyo, Japan) plus $30 \mu \mathrm{L} \mathrm{H}_{2} \mathrm{O}_{2}$. Finally, the sections were counterstained with hematoxylin (Merck, Tokyo, Japan) and NGF, TrkA and p75 were detected, respectively. The control sections were treated with normal rabbit serum (Sigma) instead of the primary antibody. The immunostained slides were scanned using the software ImagePro Plus 4.5 (Media Cybernetics, Inc., Silver Spring, MD, USA) at $20 \times$ magnification. The specificity of NGF and its receptors, TrkA and p75 antibodies have been described previously. ${ }^{25,26}$ The immunohistochemical staining was determined as positive (+), strong positive $(++)$, very strong positive $(+++)$ and negative $(-)$. Staining that was weak but higher than control was set as positive (+); the highest intensity staining was set as very strong positive $(+++)$; staining intensity between + and +++ was set as strong positive (++).

\section{Hormone assays}

Plasma concentrations of follicle-stimulating hormone (FSH) and luteinizing hormone (LH) were measured by double-antibody RIA systems using ${ }^{125}$ I-labeled radioligands with a rabbit antiserum against human FSH (\#6; provided by NIDDK NIH, Bethesda, MD, USA) and a rabbit antiserum against ovine LH (YM \#18; provided by Dr. Y. Mori, Laboratory of Veterinary Ethology, University of Tokyo). The intra- and inter-assay coefficients of variation were $9.2 \%$ and $13.2 \%$ for FSH and $8.8 \%$ and $13.0 \%$ for LH, respectively.

\section{Statistical analysis}

Statistical analysis was performed using the Student's $t$-test. Values of $\mathrm{P}<0.05$ were considered as significant.

\section{Results \\ Morphology and histology}

Morphological and histological observations of ovaries during the breeding and nonbreeding seasons are shown in Figure 1. Both the ovarian volume and weight were markedly higher in the breeding season than in the nonbreeding season (Figure $1 \mathrm{a}, \mathrm{b}$ ). Morphological
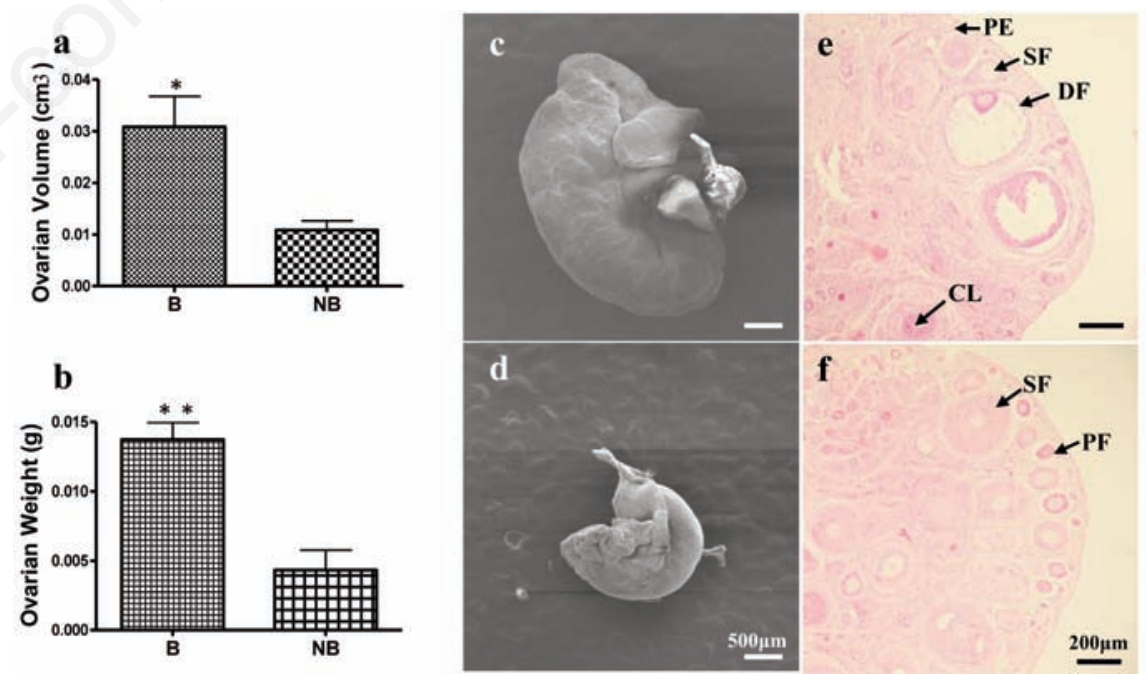

Figure 1. Morphological and histological features of ovarian tissues of the wild ground squirrel during the breeding and nonbreeding seasons. Ovarian volume (a) and weight (b). Morphological observations of ovaries in the breeding season (c) and the nonbreeding season (d). Primary follicle, secondary follicle, dominant follicle and corpus luteum in the ovaries of the breeding season (e). Primary follicles and secondary follicles in the ovaries of the nonbreeding season (f). B, breeding season; NB, the nonbreeding season; $\mathrm{PF}$, primary follicle; SF, secondary follicle; $\mathrm{AF}$, antral follicle; $\mathrm{CL}$, corpus luteum. ${ }^{*} \mathrm{P}<0.05$. Scale bars: c,d) $50 \mu \mathrm{m}$; e,f) $200 \mu \mathrm{m}$. 
observations by SEM showed that the breeding season ovary was significantly larger than that in the nonbreeding season (Figure $1 \mathrm{c}, \mathrm{d}$ ). All types of follicles as well as corpora lutea were seen in ovary of the breeding season (Figure 1e), whereas primary and secondary follicles dominated the nonbreeding season ovary with very few tertiary and none mature follicles (Figure 1f).

\section{Scanning electron microscopy}

The cuboidal cells and squamous cells of the wild ground squirrel ovaries were observed during both breeding and nonbreeding seasons (Figure 2). There were the existences of cuboidal cells, which are shaped like cubes (Figure 2a,b, yellow circle), and squamous cells (Figure 2a,b, red circle) on the surface of ovaries between the breeding and nonbreeding seasons. The enlargement images of cuboidal cells (Figure 2c) and squamous cells (Figure 2d) were shown separately. These results showed that cuboidal cells and squamous cells also existed on the ovary of wild ground squirrel during the breeding and nonbreeding seasons.

\section{Immunohistochemistry}

Immunostaining of NGF, TrkA and p75 was evaluated in OSE cells during the breeding and nonbreeding seasons (Figure 3). During the breeding season, NGF and TrkA was expressed in the cuboidal cells and the squamous cells (Figure 3 b,c,f,g). In particular, very strong immunoreactivity of TrkA was detected in the breeding period (Figure $3 \mathrm{f}, \mathrm{g}$ ). In contrast, OSE cells during the nonbreeding season showed relatively weak immunostaining for NGF and TrkA (Figure 3 j,k,n,o). Positive p75 staining was observed for cuboidal cells in the breeding season (Figure 3p) but not in other types of OSE cells (Figure 3 d,h,i). In the negative control, no signal was detected in the OSE cells during the breeding and nonbreeding seasons (Figure 3 a,e,i,m). The immunoreactivity of each staining is summarized in Table 1.

\section{Plasma concentration of $\mathrm{LH}$ and $\mathrm{FSH}$}

The profiles of plasma LH and FSH are shown in Figure 4. Plasma LH and FSH concentrations were all remarkably higher in the breeding season compared to the nonbreeding season (Figure $4 \mathrm{a}, \mathrm{b}$ ).

\section{Discussion}

This is the first study to investigate the immunolocalization of NGF and its two receptors TrkA and P75 in OSE cells of the wild ground squirrel during the breeding and nonbreeding seasons. We found that immunoreac- tivity levels for NGF, TrkA and P75 in OSE were positively correlated with the plasma concentrations of FSH and LH. These findings suggest that NGF and its receptors TrkA and P75 may be involved in the regulation of seasonal OSE changes in the wild ground squirrel.

The cyclic alternation between growth and involution of glands is a well-known phenomenon. The seasonality of ovarian mass shown in the present study agrees with other reports in this species. $^{25,27}$ In the present study, we

observed ovarian recrudescence and regression in the wild ground squirrels as judged by ovarian weight and size with significantly high weight and size in the breeding season. In addition, the histological analysis of folliculogenesis showed that primary follicles, secondary follicles, antral follicles, post-antral follicles and corpus lute $i$ were present in the breeding season, but only preantral follicles existed in the nonbreeding season. These observations demonstrate that differences in follicular

Table 1. Results of immunohistochemistry in the ovarian surface epithelium.

\begin{tabular}{lcccccc} 
& \multicolumn{3}{c}{ NGF } & \multicolumn{2}{c}{ trkA } & \multicolumn{2}{c}{ p75 } \\
& May & July & May & July & May & July \\
Squamous OSE cells & $++/+$ & ++ & +++ & + & $++/+$ & + \\
Cubodial OSE cells & $++/+$ & $/$ & ++ & $/$ & + & $/$ \\
\hline
\end{tabular}

NGF, nerve growth factor; OSE, ovarian surface epithelium; -, negative staining; +, staining; ++, strong positive staining; +++, very strong positive staining; /, no such cell type.
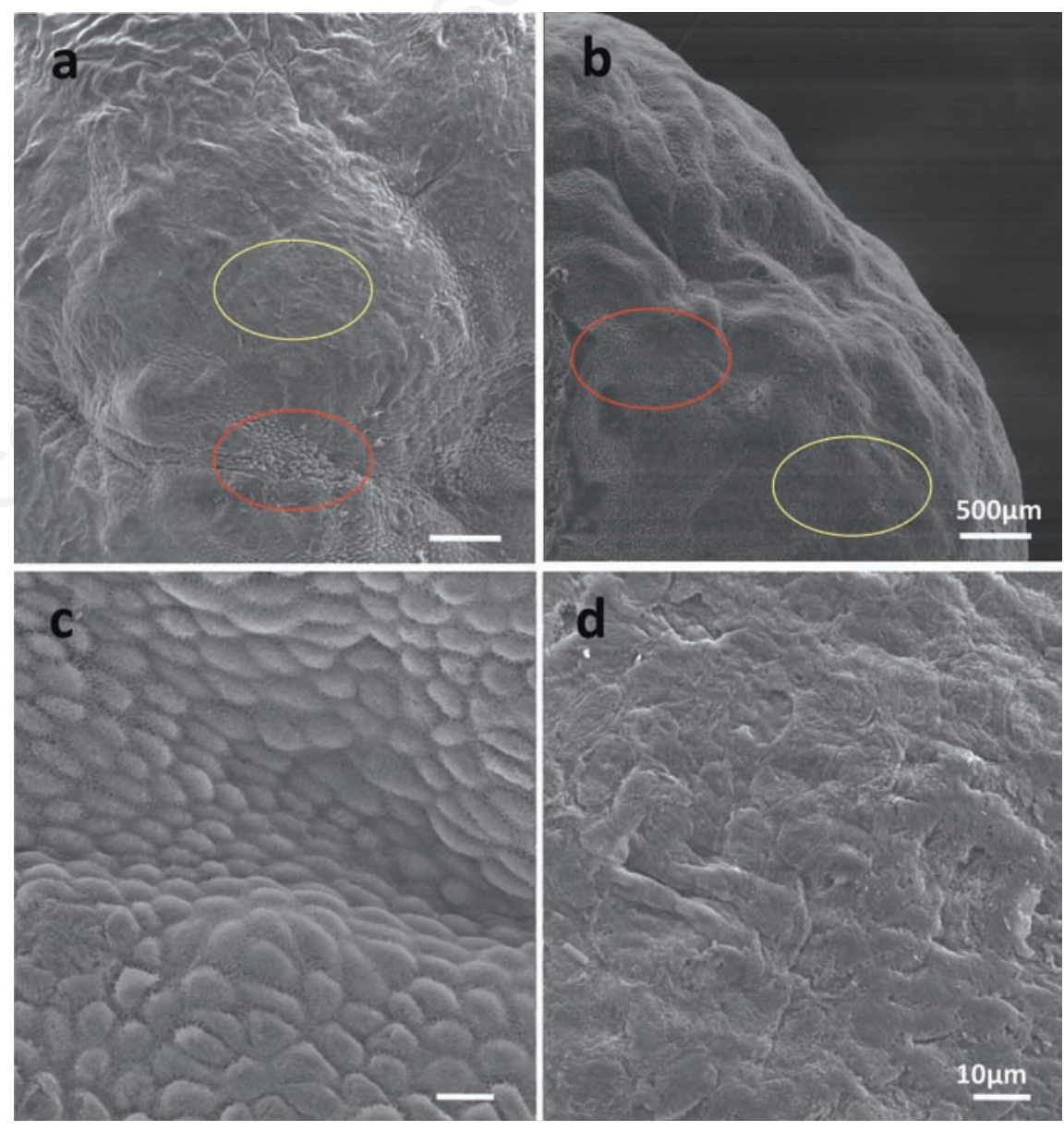

Figure 2. Evaluation of cuboidal cells and squamous cells on the ovarian surface. The ovarian surface epithelium was viewed by SEM in the breeding season (a) and nonbreeding season (b). The location of cuboidal cells and squamous cells are indicated by red and yellow circles respectively. Also shown are magnified views of the cuboidal cells (c) and squamous cells (d). Scale bars: a,b) $500 \mu \mathrm{m}$; c,d) $10 \mu \mathrm{m}$. 
development exist in the ovaries of the seasonal reproductive animal. The ovary is a rich source of multiple hormones, growth factors, and cytokines that are thus often at a higher intra-ovarian concentration than that in the serum and thus are strong candidates to regulate the OSE. ${ }^{6}$ It is reported that the OSE can secrete many growth factors, such as epidermal growth factor (EGF), transforming growth factor (TGF), insulin-like growth factor (IGF) and platelet derived growth factor (PDGF). ${ }^{28-31}$ These findings suggest that such growth factors also are strong candidates to regulate normal OSE physiology and the transformation and progression of ovarian cancers. In the present study, immunohistochemical analysis of OSE cells during the breeding and nonbreeding seasons demonstrate their capability to synthesize and secrete NGF and its receptors proteins in wild ground squirrels. Moreover, the immunostaining of NGF and its receptors TrkA and p75 were stronger in the breeding season as compared to the nonbreeding season, implying that the NGF system may be involved in regulation of OSE proliferation as well as ovarian recrudescence and regression. The female reproductive system undergoes a number of programmed cyclical processes during the ovulatory cycle. The OSE cells actively participate in the cyclical ovulatory rupture and repair processes. NGF and its receptors, under the influence of gonadotropins and/or ovarian hormones, play a crucial regulatory role in these processes. ${ }^{32-34}$ The roles of NGF and its receptors in ovary of the wild ground squirrel have been studied, indicating in situ synthesis and secretion of NGF and its receptors in ovaries of the wild ground squirrel, where the role of NGF might be mediated via both receptors TrkA and P75 to affect follicular development. ${ }^{25}$ Moreover, the expression levels of NGF and its receptors, TrkA and p75, were significantly higher in the breeding season compared to the nonbreeding season, suggesting that the NGF system may be involved in the regulation of ovarian function changes. ${ }^{25}$ The OSE plays an important role in normal ovarian physiology. During each reproductive cycle, the OSE takes part in the cyclical ovulatory ruptures and repair and OSE on the preovulatory follicle undergoes apoptosis at the time of ovulation. ${ }^{35}$ The present findings that NGF and its receptors were expressed in OSE cells of the wild ground squirrel during the breeding and nonbreeding seasons imply that NGF and its receptors contribute to events either leading to or associated with the ovulatory process in wild ground squirrels.

There is increasing evidence for indirect effects of gonadotropins on OSE proliferation via cross-talk with growth factors. ${ }^{6}$ The highdensity OSE cell culture might resemble the microenvironment of preovulatory OSE cells and, in response to $\mathrm{FSH}$ and $\mathrm{LH}$, the OSE undergoes apoptosis whereas the sparse or subconfluent OSE cells might mimic the ruptured the OSE cells and gonadotropins may have different effects, including stimulation of OSE proliferation. ${ }^{6}$ In addition, FSH- and hCGstimulated steady state levels of keratinocyte growth factor (KGF), hepatocyte growth factor (HGF) and Kit ligand mRNA in bovine OSE cells suggest that the effects of gonadotropins could be mediated by the local release of growth-promoting factors. ${ }^{36}$ Previous studies demonstrated that treatment with FSH and LH significantly increased EGF receptor mRNA and protein in preneoplastic OSE, indicating that this regulation of the mitogenic activity of stimulatory growth factors such as EGF may be a mechanism by which gonadotropins promote ovarian cancer development in terms of neoplastic conversion and growth potential. ${ }^{6,37}$ Evidence also indicates that perimenopausal OSE could express FSHR. NGF might deregulate expression of FSHR in the OSE and secretion of FSH from the pituitary. ${ }^{38}$ In addition, human epithelial ovarian cancer showed high NGF expression, as NGF regulates calreticulin protein levels in epithelial ovarian cells through TrkA receptor activation. ${ }^{39}$ Therefore, the present results provide experimental evidences that, correlated with FSH and LH levels, the stronger positive staining of NGF, trkA and p75 in the OSE cells during the breeding season supports the view that the effects of growth factors on the OSE are regulated by gonadotropins. ${ }^{40} \mathrm{In}$ summary, the correlation between changes in the immunoreactivity of NGF, trkA and p75 and plasma FSH and LH concentrations in this study suggest that the NGF system may be involved in regulation of seasonal changes in the OSE of wild ground squirrels.

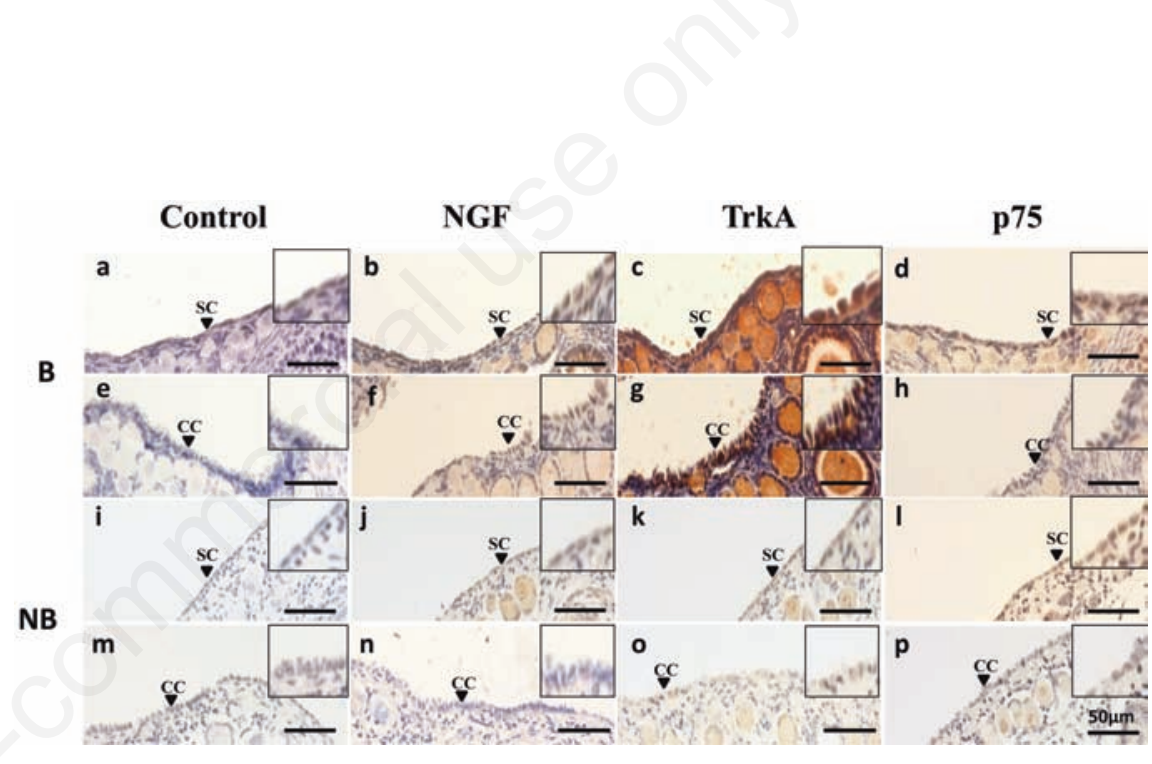

Figure 3. Immunohistochemical localization of NGF ligand and receptors in the ovarian surface epithelium during the breeding (B) and nonbreeding (NB) seasons. The first column $(\mathrm{a}, \mathrm{e}, \mathrm{i}, \mathrm{m})$ represents negative control staining; the second column $(\mathrm{b}, \mathrm{f}, \mathrm{j}, \mathrm{n})$, the third column $(c, g, k, o)$, and the fourth column $(d, h, l, p)$ represent immunostaining with antibodies against NGF, TrkA and p75, respectively. SC, squamous cell; CC, cuboidal cell. Scale bars: $50 \mu \mathrm{m}$.

a

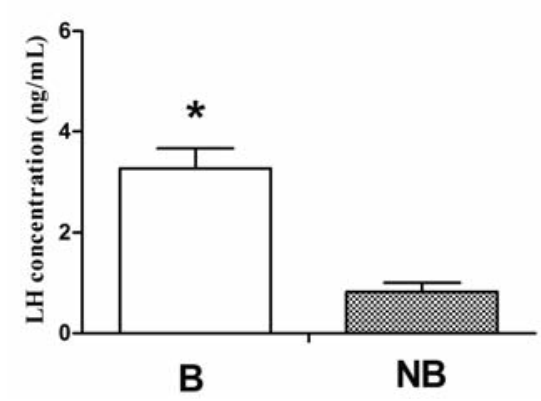

\section{b}

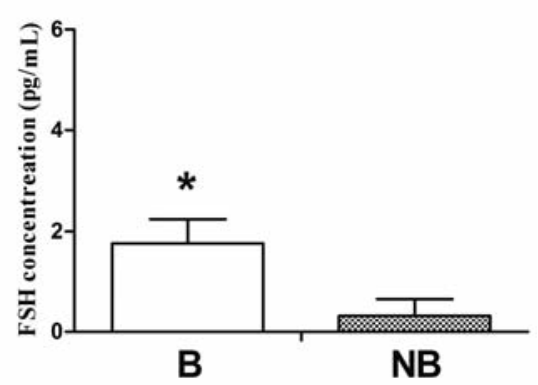

Figure 4. Plasma LH (a) and FSH (b) levels in wild ground squirrel during the breeding period $(B)$ and nonbreeding period $(\mathrm{NB})$. Bars represent means + SD for five independent experiments. ${ }^{*} \mathrm{P}<0.05$. 


\section{References}

1. Risch HA. Hormonal etiology of epithelial ovarian cancer, with a hypothesis concerning the role of androgens and progesterone. $\mathrm{J}$ Natl Cancer Inst 1998;90:1774-86.

2. Cajander S. Structural alterations of rabbit ovarian follicles after mating with special reference to the overlying surface epithelium. Cell Tissue Res 1976;173:437-49.

3. Blaustein A. Surface (germinal) epithelium and related ovarian neoplasms. Pathol Annu 1981;16 Pt 1:247-94.

4. Clow OL, Hurst PR, Fleming JS. Changes in the mouse ovarian surface epithelium with age and ovulation number. Mol Cell Endocrinol 2002;191:105-11.

5. Gillett WR, Mitchell A, Hurst PR. A scanning electron microscopic study of the human ovarian surface epithelium: characterisation of two cell types. Hum Reprod 1991;6:645-50.

6. Wong AS, Leung PC. Role of endocrine and growth factors on the ovarian surface epithelium. J Obstet Gynaecol Res 2007; 33:3-16.

7. Scully RE. Pathology of ovarian cancer precursors. J Cell Biochem 1995;23:208-18.

8. Berchuck A, Carney M. Human ovarian cancer of the surface epithelium. Biochem Pharmacol 1997;54:541-4.

9. Kruk PA, Uitto VJ, Firth JD, Dedhar S, Auersperg N. Reciprocal interactions between human ovarian surface epithelial cells and adjacent extracellular matrix. Exp Cell Res 1994;215:97-108.

10. Levi-Montalcini R. The nerve growth factor 35 years later. Science 1987;237:1154-62.

11. Johnson D, Lanahan A, Buck CR, Sehgal A, Morgan C, Mercer E, et al. Expression and structure of the human NGF receptor. Cell 1986;47:545-54.

12. Kaplan DR, Martin-Zanca D, Parada LF. Tyrosine phosphorylation and tyrosine kinase activity of the trk proto-oncogene product induced by NGF. Nature 1991;350: 158-60.

13. Snider WD. Functions of the neurotrophins during nervous system development: what the knockouts are teaching us. Cell 1994; 77:627-38.

14. Russo MA, Giustizieri ML, Favale A, Fantini MC, Campagnolo L, Konda D, et al. Spatiotemporal patterns of expression of neurotrophins and neurotrophin receptors in mice suggest functional role in testicular and epididymal morphogenesis. Biol Reprod 1999;61:1123-32.

15. Dissen GA, Parrott JA, Skinner MK, Hill DF, Costa ME, Ojeda SR. Direct effects of nerve growth factor on thecal cells from antral ovarian follicles. Endocrinology 2000;141:4736-50.

16. Ojeda SR, Romero C, Tapia V, Dissen GA. Neurotrophic and cell-cell dependent control of early follicular development. Mol Cell Endocrinol 2000;163:67-71.

17 Dissen GA, Romero C, Hirshfield AN, Ojeda SR. Nerve growth factor is required for early follicular development in the mammalian ovary. Endocrinology 2001;142:2078-86.

18. Salas C, Julio-Pieper M, Valladares M, Pommer R, Vega M, Mastronardi C, et al. Nerve growth factor-dependent activation of trkA receptors in the human ovary results in synthesis of follicle-stimulating hormone receptors and estrogen secretion. J Clin Endocrinol Metab 2006;91:2396-403.

19. Levanti MB, Germanà A, Abbate F, Montalbano G, Vega JA, Germanà G. TrkA and p75NTR in the ovary of adult cow and pig. $J$ Anat 2005;207;93-6.

20. Abir R, Fisch B, Jin S, Barnnet M, BenHaroush A, Felz C, et al. Presence of NGF and its receptors in ovaries from human fetuses and adults. Mol Hum Reprod 2005;11:229-36.

21. Shi Z, Arai KY, Jin W, Weng Q, Watanabe G, Suzuki AK, Taya K. Expression of nerve growth factor and its receptors NTRK1 and TNFRSF1B is regulated by estrogen and progesterone in the uteri of golden hamsters. Biol Reprod 2006;74:850-6.

22. Pudney J, Canick JA, Clifford NM, Knapp JB, Callard GV. Location of enzymes of androgen and estrogen biosynthesis in the testis of the ground squirrel. Biol Reprod 1985;33:971-80.

23. Landau IT, Holmes WG. Mating of captive thirteen-lined ground squirrels and the annual timing of estrus. Horm Behav 1988;22:474-87.

24. Strauss A, Hoffmann IE, Walzl M, Millesi E. Vaginal oestrus during the reproductive and non-reproductive period in European ground squirrels. Anim Reprod Sci 2009;112:362-70.

25. Li B, Sheng X, Bao L, Huang S, Li Q, Liu Y, et al. Seasonal changes in expression of nerve growth factor and its receptors TrkA and p75 in the ovary of wild ground squirrel. $\mathrm{J}$ Ovarian Res 2014;7:3.

26. Li B, Sheng X, Song M, Zhang H, Weng J, Zhang M, et al. Expression of nerve growth factor and its receptors TrkA and p75 in the uterus of wild female ground squirrel (Citellus dauricus Brandt). Gen Comp Endocrinol 2012;176:62-9.

27. Li X, Zhang H, Sheng X, Li B, Zhou J, Xu M, et al. Immunoreactivities of androgen receptor, estrogen receptors, P450arom, P450c17 proteins in wild ground squirrels ovaries during the nonbreeding and breeding seasons. J Ovarian Res 2012;5:26.

28. Ahmed N, Maines-Bandiera S, Quinn MA, Unger WG, Dedhar S, Auersperg N. Molecular pathways regulating EGF-induced epitheliomesenchymal transition in human ovarian surface epithelium. Am J Physiol Cell Physiol 2006;290:1532-42.

29. Nilsson E, Doraiswamy V, Parrott JA,
Skinner MK. Expression and action of transforming growth factor beta (TGFbetal, TGFbeta2, TGFbeta3) in normal bovine ovarian surface epithelium and implications for human ovarian cancer. Mol Cell Endocrinol 2001;182:145-55.

30. Gubbay 0, Guo W, Rae MT, Niven D, Howie AF, McNeilly AS, et al. Anti-inflammatory and proliferative responses in human and ovine ovarian surface epithelial cells. Reproduction 2004;128:607-14.

31. Dabrow MB, Francesco MR, McBrearty FX, Caradonna S. The effects of platelet-derived growth factor and receptor on normal and neoplastic human ovarian surface epithelium. Gynecol Oncol 1998;71:29-37.

32. Weng Q, Shi Z, Kawaguchi M, Watanabe G, Taya K. Expression of nerve growth factor and its receptors trkA and p75 and inhibin alpha-subunit in the ovarian interstitial cells of lactating golden hamsters. J Reprod Dev 2008;54:397-401.

33. Weng Q, Shi Z, Tukada J, Watanabe G, Taya K. Immunodetection of NGF, trkA, p75 and inhibin alpha-subunit in interstitial cells of golden hamsters treated with hCG. J Reprod Dev 2009;55:622-8.

34. Weng Q, Shi Z, Watanabe G, Taya K. Immunolocalization of NGF and its receptors trkA and p75 in the oviducts of golden hamsters during the estrous cycle. Exp Anim 2009;58:543-6.

35. Murdoch WJ. Programmed cell death in preovulatory ovine follicles. Biol Reprod 1995;53:8-12.

36. Parrott JA, Mosher R, Kim G, Skinner MK. Autocrine interactions of keratinocyte growth factor, hepatocyte growth factor, and kit-ligand in the regulation of normal ovarian surface epithelial cells. Endocrinology 2000;141:2532-9。

37. Choi JH, Choi KC, Auersperg N, Leung PC. Gonadotropins upregulate the epidermal growth factor receptor through activation of mitogen-activated protein kinases and phosphatidyl-inositol-3-kinase in human ovarian surface epithelial cells. Endocr Relat Cancer 2005;12:407-21.

38. Bose CK. Role of nerve growth factor and FSH receptor in epithelial ovarian cancer. Reprod Biomed Online 2005;11:194-7.

39. Vera C, Tapia V, Kohan K, Gabler F, Ferreira A, Selman A, et al. Nerve growth factor induces the expression of chaperone protein calreticulin in human epithelial ovarian cells. Horm Metab Res 2012;44:639-43.

40. Ji Q, Liu PI, Chen PK, Aoyama C. Follicle stimulating hormone-induced growth promotion and gene expression profiles on ovarian surface epithelial cells. Int J Cancer 2004; 112:803-14. 